\title{
NOMES NUS E O PARÂMETRO NOMINAL NO PORTUGUÊS BRASILEIRO*
}

Ana Müller**

\section{Introdução}

$\mathrm{E}$

m Chierchia (1998) temos uma visão de como as categorias do nome comum (N) e do sintagma nominal (SN) são mapeadas a suas denotações em diferentes línguas. Para o autor, a denotação de um $\mathrm{N}$ ou de um SN pode variar de língua para língua. Em alguns casos ela pode ser argumental e denotar diretamente uma entidade (tipo e). Em outros casos, ela pode ser predicativa e denotar uma propriedade (tipo <e, $\gg$ ). Esta visão opõe-se à visão tradicionalmente assumida de que Ns e SNs são sempre predicados e que apenas Sintagmas de Determinante (SDs) podem ser argumentos como tem sido apresentado na literatura (cf. Stowell, 1989; Longobardi, 1994).

* Este trabalho foi apresentado no II Workhop A Semântica do Português Brasileiro. Agradeço à audiência pelos comentários. Em particular, agradeço a Barbara Partee pela discussão cuidadosa de uma primeira versāo deste trabalho.

** Universidade de São Paulo. 
MÜLLER, A. Nomes nus e o parâmetro nominal...

Chierchia (1998) defende as seguintes teses:

(i) Existe um parâmetro semântico, Parâmetro Nominal (The Nominal Mapping Parameter) que permite que projeções nominais máximas sem determinante sejam predicativas [+pred] (i.e., elas denotam propriedades) ou argumentais $[+\arg ]$ (i.e., elas denotam espécies ou (individuos). ${ }^{\prime}$

(ii) A fixação deste parâmetro tem conseqüências tanto para a morfologia quanto para a sintaxe de cada língua.

Como conseqüência, temos uma tipologia para as línguas naturais que prevê a existência de três tipos de línguas.

1. Línguas do tipo [+arg, -pred]. Nestas línguas Ns e SNs obrigatoriamente referem-se a espécies. Um exemplo deste tipo seria o Chinês. Essas línguas possuem as seguintes características:

(i) SNs nus ocorrem livremente como argumentos.

(ii) Uma vez que espécies não diferenciam entre instanciações singulares ou plurais, estas línguas não possuem um contraste morfológico entre Ns e SNs singulares ou plurais. Conseqüentemente, nessas línguas nomes nus não são marcados para número.

(iii) Essas línguas não permitem que Ns ou SNs se combinem diretamente com numerais, mas exigem a presença de classificadores, pois as denotações de seus SNs não são especificados para número.

2. Línguas do tipo [-arg, + pred]. Nessas línguas $\mathrm{N}$ e SNs obrigatoriamente referem-se a propriedades. Um exemplo típico seria o Francês. Línguas [-arg, +pred] possuem as seguintes características:

1 Propriedades, em semântica formal, são funções de mundos possíveis a conjuntos de indivíduos. Por exemplo, a denotação do nome professor é uma propriedade, ou seja, uma função que determina, em cada mundo, o conjunto dos professores naquele mundo. Ver, por exemplo, Dowty et al.(1981). Espécies são consideradas entidades do mundo tal como Fernando Henrique ou Gugu. A referência clássica aqui é Carlson (1977). 
(i) Apenas sintagmas de determinante (SDs) podem ser argumentos - a presença de um determinante é obrigatória

(ii) Um determinante nulo é possivel apenas sob condições de licenciamento de categorias vazias.

(iii) Estas línguas possuem morfologia de número, pois individuos plurais podem ser construídos a partir de propriedades de nomes comuns (conjuntos de entidades atômicas em cada mundo).

(iv) Os únicos $\mathrm{SNs}$ nus possíveis para estas línguas são os plurais nus - o determinante nulo está definido apenas para nomes plurais.

3. Línguas do tipo [+arg, +pred]. Nessas línguas Ns e SNs podem se referir a propriedades ou a espécies. Um exemplo deste tipo de língua seria o Inglês. Línguas $[+\arg ,+$ pred] possuem as seguintes características:

(i) Argumentos nus são possiveis em certas circunstâncias: (a) Quando o SN nu é de tipo [+arg] (massivo); (b) Quando o SN nu é [+pred] (contável) e capaz de ter seu tipo mudado para espécie. ${ }^{2}$

(ii) Essas línguas possuirão morfologia de número para seus nomes contáveis, pois como se viu acima, indivíduos plurais podem ser construídos a partir das denotações dos conjuntos de elementos atômicos que constituem as denotações destes nomes em cada mundo.

(iii) Se ocorrem nominais nus nessas línguas, eles serão plurais nus - a operação de mudança de tipo só é possível para plurais, pois esta é uma operação que transforma predicados em espécies e espécies só podem ser construídas a partir de indivíduos plurais.

2 Operações de mudança de tipo ("type-shiffing") são admitidas em semântica formal estando submetidas a certas restrições. Estas operações mudam o tipo semântico original da categoria sintática do elemento sobre o qual operam. Ver Partee (1987). 
O objetivo deste artigo é avaliar as conseqüências empíricas do comportamento do Português Brasileiro para o Parâmetro de Mapeamento Nominal. ${ }^{3}$ Alguns fatos do PB são aparentemente contrários às previsões do Parâmetro de Mapeamento Nominal. O PB, como o Chinês, possui um SN contável sem número que é bastante produtivo. Mas, ao contrário do que é previsto para este tipo de língua, no PB:

(i) Há um contraste entre o singular e o plural.

(ii) Há uma distinção entre nomes de massa e nomes contáveis.

(iii) A ocorrência dos nomes nus é aparentemente livre.

Estes fatos questionam a existência de um parâmetro semântico que determina as denotações possíveis para sintagmas nominais nas línguas naturais, como proposto por Chierchia (1998). Questionam também a possibilidade de se prever o comportamento morfológico e sintático de nomes comuns e sintagmas nominais a partir de suas denotações e vice versa.

\section{A ontologia de Chierchia para a gramática universal}

Chierchia (1998) propõe que o aparato cognitivo humano 'vê' o mundo como contendo tanto entidades singulares quanto entidades plurais. Isto pode ser representado em uma estrutura de reticulados como a ilustrada em (1). ${ }^{4}$

$$
\begin{aligned}
& \{a, b, c) \\
& \{a, b\}\{a, c\}\{a, b\} \\
& a b c
\end{aligned}
$$

3 Veja Chung (2000) e Schmitt e Munn (1999) para uma discussão semelhante do Parâmetro do Mapeamento Nominal.

40 modelo de Chierchia é intensional, leva em conta mundos possíveis. Minhas ilustrações, por outro lado, são todas extensionais, isto é, deixam de lado a variação da denotação de cada constituinte em diferentes mundos. 
Em (2), $a, b$ e $c$ representam a denotação de Ns ou SNs singulares, ou seja, representam indivíduos singulares (átomos), tais como Jorge ou aquela mesa. Conjuntos formados por mais de um átomo como $\{a, b\},\{a, c\},\{b, c\} \mathrm{e}$ $\{a, b, c\}$ representam as denotações de Ns ou SNs plurais, ou seja, indivíduos plurais, como Jorge e Maria ou aquelas mesas, como ilustrado em (3).

$$
\text { [[nomes contáveis singulares }]]=\mathrm{a} \quad \mathrm{b} \quad \mathrm{c}
$$

$$
[\text { [nomes contáveis plurais }]]=\frac{\{a, b, c\}}{\{a, b\}\{b, c\}\{a, c\}}
$$

Já a denotação predicativa dos nomes de massa está ilustrada em (4). Estes nomes são neutros em relação à distinção entre singular e plural, pois, de suas denotações, fazem parte, tanto indivíduos singulares, quanto indivíduos plurais. Em (5) temos representada a denotação de um nome de massa argumental. Esta é representada por uma entidade que consiste em um amálgma de todas as entidades que pertencem à denotação do predicado correspondente.

$$
\{\mathrm{a}, \mathrm{b}, \mathrm{c}\}
$$

$$
\begin{aligned}
& {[[\text { nomes de massa predicativos }]]=\{a, b\}\{a, c\}\{a, b\}} \\
& \text { a b c } \\
& \text { (5) } \quad[\text { [nomes de massa argumentais }]]=\quad\{a, b, c\}
\end{aligned}
$$

Para Chierchia (1998), "A extensão de nomes como água é análoga à de nomes como mobilia, sendo que a única diferença é que o que conta como uma parte mínima de água é de certa forma vago e pode variar de contexto a contexto" (tradução minha, p. 347). Em outras palavras, para Chierchia nomes de massa e nomes comuns denotam objetos de um mesmo tipo, a diferença entre ambos é a maior ou menor precisão com que estão delimitados os átomos de suas denotações.

As propriedades típicas dos nomes de massa podem ser derivadas desta proposta que, ao mesmo tempo, explica por que nomes de massa e nomes plurais têm comportamentos semelhantes: ambos possuem pluralidades em suas denotações. A impossibilidade de pluralização de um nome de massa é conseqüência do fato de que esses nomes já contêm entidades plurais em suas denotações. 
Por outro lado, a impossibilidade de se contar diretamente um nome de massa segue do fato de que sua denotação não fornece um critério único segundo o qual se possa proceder uma contagem de entidades homogêneas.

A partir do trabalho clássico de Carlson (1977), espécies são consideradas entidades/objetos semelhantes a indivíduos, com a diferença de que suas manifiestações espaço-temporais são tipicamente descontínuas. Espécies são regularidades que ocorrem na natureza. A cada propriedade considerada "natural" corresponde uma espécie. E vice-versa, a toda espécie natural corresponderá uma propriedade (a propriedade de pertencer àquela espécie).

A correspondência entre propriedades e espécies sugere que passamos facilmente de um conceito a outro. Assim, Chierchia (1998) propõe a existência de operações de mudança de tipo capazes de transformar uma propriedade em uma espécie e vice-versa. Uma espécie pode ser manufaturada a partir de uma propriedade tomando-se o maior membro de sua extensão (em qualquer mundo) e uma propriedade pode ser manufaturada a partir de uma espécie tomando-se todas as entidades singulares e plurais que podem ser geradas a partir da denotação da espécie. A correspondência entre propriedades e espécies, juntamente com os operadores de mudança de tipo correspondentes, estão ilustrados em (6) (novamente para uma espécie com apenas três realizações).

(6) Propriedade

$\{a, b, c\}$
$\{a b\}\{a c\}\{b, c\}$
$a b c$

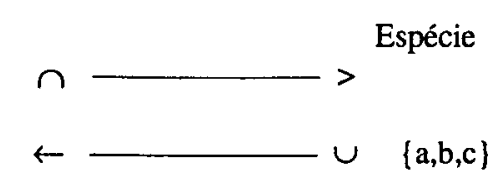

\section{Nominais nus no Português Brasileiro}

É importante começar estabelecendo que, ao contrário de outras línguas românicas, no PB o uso dos SNs sem número é extremamente freqüente. Desta maneira, o comportamento massivo do nominal sem número não parece ser apenas um efeito de uma aplicação do "triturador universal" (Pelletier, 1975: uma "máquina" que "tritura" as denotações de nomes contáveis e as transforma em substâncias massivas). As sentenças em (8) e (10) são respostas perfeitamente comuns e corriqueiras às perguntas (7) e (9). Todas elas fazem uso do nominal sem número. 
(7) O que que você fez hoje de manhã?

(8) a. Eu li revista.

b. Eu comprei sapato.

c. Eu tirei fotografia.

(9) Quem gosta de brincar?

(10) a. Criança gosta de brincar.

b. Cachorro gosta de brincar.

c. Brasileiro gosta de brincar.

Em Português Brasileiro, nominais nus sem número e plurais nus parecem ocorrer livremente em posição de argumento como ilustrado em (8) e (10). Nossa primeira hipótese então seria: Talvez o PB seja uma língua [+arg, -pred] - uma língua na qual os nomes e os sintagmas nominais sem número referem-se diretamente a espécies.

Alguns fatos apoiam essa hipótese. Primeiro, temos que argumentos nus sem número ocorrem em sentenças genéricas com uma leitura universal como ilustram (11) e (12) e suas respectivas paráfrases. Neste aspecto, os nomes nus em PB são semelhantes aos plurais nus do inglês.

(11) Cachorro gosta de osso. ("Todo cachorro gosta de (todo) osso")

(12) Professor é trabalhador. ("Todo professor é trabalhador")

Em segundo lugar, temos que os nominais sem número não estabelecem relações de escopo. Eles sempre tomam um escopo estrito com respeito à negação e a contextos intensionais. Eles também não possuem leituras específicas (Schmitt; Munn, 1999). Ou seja, não possuem todas as interpretações usuais de um SD indefinido.

Compare as sentenças em (13a)-(15a) às sentenças em (13b)-(15b). A única diferença entre elas é que nas primeiras temos um nominal nu e nas últimas temos a presença do artigo indefinido. No entanto, apenas nas sentenças em b, temos a possibilidade de escopo amplo, ou seja, apenas nestas sentenças, os sintagmas indefinidos um livro escolar, uma casa e um cachorro podem ter uma leitura de escopo largo como indicam as paráfrases correspondentes. Uma outra paráfrase é possível para as sentenças em $b$, na qual elas seriam equivalentes às sentenças em $a$, diferindo destas apenas pelo número de entidades implicadas pelo indefinido. 
a. Ele não encontrou livro escolar na FNAC.

b. Ele não encontrou um livro escolar na FNAC.

"Tem um certo livro escolar que ele não encontrou na FNAC"

(14) a. Eu estou procurando casa para alugar.

b. Eu estou procurando uma casa para alugar.

"Tem uma certa casa que eu estou procurando"

a. Pedro viu cachorro no jardim às 3 , às $4 \mathrm{e}$ às 5 datarde.

b. Pedro viu um cachorro no jardim às 3 , às $4 \mathrm{e}$ às 5 da tarde.

"Tem um cachorro que Pedro viu no jardim às 3 , às $4 \mathrm{e}$ às 5 da tarde"

Finalmente, sintagmas nominais sem número possuem um comportamento massivo em PB. Uma evidência de seu comportamento massivo vem do fato de que os nomes sem número, além de não serem marcados para número, comportam-se como possuindo uma denotação não-discreta. Uma sentença como (16) significa que Jorge lê um número indefinido de revistas depois do jantar. $\mathrm{Na}$ verdade, Jorge não precisa nem ler uma revista inteira. O memo acontece em (17) onde, tanto o número de secretários, quanto o número de discursos é indefinido.

(16) Jorge sempre lê revista depois do jantar.

(17) Secretario de prefeito escreve discurso todo dia.

Aqui é necessário pensar em nome de massa nos termos da proposta de Chierchia, i.e., um termo cuja denotação é neutra em respeito à diferença singular-plural: “...dizer que todos os membros da categoria SN são massivos não significa dizer que alguma coisa semelhante à distinção massivo/contável não possa ser encontrada..." (Chierchia, 1988, p. 355, tradução minha).

Uma outra evidência do comportamento massivo dos sintagmas nominais sem número é o fato de que estes nominais não são capazes de fornecer um conjunto sobre o qual o quantificador distributivo cada possa distribuir. Cada é um quantificador distributivo que exige um conjunto de entidades discretas sobre as quais possa distribuir (Gomes, 2000; Negrão, 2001). Note que a sentença (18) com o nominal nu é agramatical, ao passo que a sentença (19) com o artigo indefinido é perfeita. Em (19), podemos distribuir um livro por aluno, ao passo que não há uma distribuição possível para (18). 
(19) Cada aluno leu um livro de linguística.

Os nominais sem número do $\mathrm{PB}$ coocorrem com quantificadores tipicamente massivos como em (20), com a palavra suficiente que só pode ser usada com termos massivos (21), e com "classificadores" massivos (22) (cf. Bunt, 1985).

(20) Tem muita mala no carro.

(21) Eu já escrevi carta suficiente por hoje.

(22) Eu queimei 10 quilos de livro hoje.

No entanto, a hipótese de que o Português Brasileiro é [+arg,-pred] apresenta problemas. Primeiramente, o PB não deveria possuir um contraste morfológico entre o nomes singulares e nomes plurais. Entretanto, a língua possui justamente este contraste e ele tem um signicado semântico. A diferença entre o número de meninos brincando - em (23a), apenas um menino brinca e em (23b) este número é de dois ou mais - é dada pela morfologia plural.

a. O menino está brincando.

b. Os meninos estão brincando.

Já as sentenças em (24) mostram que enquanto o nominal sem número (24a) é completamente neutro em relação à quantidade de quantos chifres temos para cada unicórnio, o acréscimo do plural em (24b) nos diz que temos dois ou mais chifres por unicórnio.

a. Unicórnio tem chifre.

b. Unicórnios tem chifres.

Segundo, o plural do PB comporta-se como outros plurais conhecidos. Assim, o plural de um nome contável em PB pode indicar tanto uma pluralidade de indivíduos, quanto uma pluralidade de espécies. O plural de um típico nome de massa, entretanto, indica apenas uma pluralidade de espécies (cf. Chung, 2000). Comparem-se as sentenças em (25) às sentenças em (26). Assim (26a) pode significar que eu comprei muitos livros ou muitos tipos de livros. Por outro lado, (26b) significa apenas que eu comprei muitos tipos de óleos.

a. Eu comprei muito livro.

b. Eu comprei muito óleo. 
a. Eu comprei muitos livros.

b. Eu comprei muitos óleos.

Terceiro, o PB deveria ser uma língua que necessita aplicar classificadores ao SN para proceder a contagens, mas não é. Pelo contrário, determinantes cardinais podem ser usados diretamente com o nome comum sem qualquer classificador como exemplificam as sentenças (27)-(29).

(27) Ele viu dois ratos de novo.

(28) Tinha uma mulher chamada Susan.

(29) Cinco gatinhos é muito.

Finalmente, nossa língua também possui um plural nu com uma possível interpretação de espécie como ilustram as sentenças (30) e (31).

(30) Cachorros gostam de ossos.

(31) Professores trabalham muito.

\section{Análises Possíveis}

Vamos agora discutir se, diante dos dados do $\mathrm{PB}$, a manutenção do Parâmetro Nominal é possível. Como resultado da argumentação apresentada na seção 2, podemos concluir que o PB não é uma língua [+arg, -pred] como o Chinês. Talvez o PB seja de tipo [+arg, +pred] como o Inglês. Neste tipo de língua, nomes de massa possuem denotações de tipo [ $+\arg ]$ e nomes contáveis possuem denotações de tipo [+pred]. Uma vez que a língua possui as duas opções para as denotações de SNs, ela é capaz de empregar operações de mudança de tipo que tranformam denotações de nomes contáveis (propriedades) em espécies (indivíduos).

Um resultado positivo desta análise seria a explicação automática da ocorrência livre de argumentos nus no PB. Por outro lado, esta análise deixa sem explicação o fato de que nomes nus contáveis não precisam ser flexionados para o plural em PB. Eles são necessariamente plurais em Inglês e outras línguas semelhantes. Um outro fato que ficaria sem explicação é a quase inexistência de uma distinção entre termos massivos e termos contáveis em PB, por oposição a sua presença bastante forte no Inglês. 
Entretanto, a previsão de que SNs nus contáveis em posições argumentais sejam plurais é uma consequiência da denotação que Chierchia 1998 atribui a nomes contáveis. Para o autor, esta denotação compõe-se apenas de átomos. $\mathrm{E}$ uma denotação atômica não pode ser transformada em espécie porque espécies não podem possuir apenas instâncias singulares em cada mundo. Assim, operação de mudança de tipo de predicados a espécies está definida apenas para plurais nos moldes de Chierchia (1998).

Uma solução possível seria revisar a ontologia proposta por Chierchia (1998) levando em conta que os dados do PB apontam para o fato de que a denotação do nome comum e dos SNs nesta língua não é marcada para número. Neste sentido, a denotação de nominais sem número no $\mathrm{PB}$ inclui tanto indivíduos singulares quanto indivíduos plurais. Estes SNs são predicados massivos [+pred] (Müller, 2001). Como uma denotação massiva de um predicado inclui indivíduos plurais, $\mathrm{SNs}$ sem número em $\mathrm{PB}$ podem mudar seu tipo para espécies.

Línguas como o Inglês, por outro lado, possuem apenas átomos nas denotações de seus nomes contáveis. Por esta razão, apenas seus plurais podem ser transformados em espécies. Estas línguas, portanto, possuem apenas plurais nus.

Seria então possível classificar o PB como $[-$ arg, +pred $]$ juntamente com as outras línguas românicas? Línguas $[+$ arg, +pred] projetam obrigatoriamente um Determinante, pois, nessas línguas, apenas Sintagmas de Determinante podem ser argumentos. Determinantes nulos podem ocorrer apenas sob condições de licenciamento de categorias vazias. Desta forma, espera-se determinantes nus em posições de objeto, mas não como sujeitos de orações principais.

Entretanto, nominais sem número ocorrem de maneira aparentemente livre em posição de sujeito em PB. Vamos deixar esta questão por aqui e apontar que além desta questão outras também se colocam:

(i) Por que uma língua teria tanto um SN sem número quanto um plural nu?

(ii) Qual seria a causa de uma assimetria na distribuição dos plurais nus e dos sintagmas sem número: os SNs sem número são agramaticais como sujeitos de sentenças episódicas, o mesmo não acontece com os plurais nus.

(32) *Médico está trabalhando muito agora neste hospital.

(33) Médicos estão trabalhando muito agora neste hospital. 


\section{Comentários finais}

Diante da discussão realizada acima, qual seria o significado de línguas como o Português Brasileiro para o Parâmetro Nominal?

A resposta depende do quanto se estiver comprometido com a ontologia proposta por Chierchia (1998). Se se acredita, como Chierchia, que propriedades "singulares" e propriedades "plurais" devem ser as mesmas em todas as línguas, o parâmetro não se sustenta. Os dados do $\mathrm{P}$ mostram que a denotação de nossos nominais sem número não consiste apenas de átomos.

Por outro lado, se se acredita que a relação entre os nominais "singulares" e "plurais" podem variar de uma língua a outra, então o insight central da teoria de Chierchia - a visão de que nomes e sintagmas nominais podem denotar tanto espécies quanto predicados em diferentes línguas - poderia ser mantido.

\section{RESUMO}

Para Chierchia (1998), a denotação de um nome ou de um sintagma nominal pode variar de língua para língua segundo um Parâmetro Nominal (PN). Em alguns casos ela pode ser argumental e denotar diretamente uma entidade. Em outros, ela pode ser predicativa e denotar uma propriedade. A fixação deste parâmetro tem conseqüências tanto para a morfologia quanto para a sintaxe de cada língua. $O$ artigo avalia o comportamento do Português Brasileiro frente ao PN e sua classificacão diante da tipologia de línguas resultante da existência deste.

Palavras-chave: semântica formal, nomes nus, parâmetros.

\section{ABSTRACT}

Chierchia (1998) claims that the denotation of nominals may vary from one language to another depending on a Nominal Mapping Parameter (NMP). In some cases, nominals may straightforwardly denote entities, in others, they may denote properties. The setting of the NMP affects both the morphology and the syntax of a language. This article evaluates the behavior of Brazilian Portuguese as far as the predictions of the PN are concerned. Its also discusses BP's position regarding the typology of languages that follows from the parameter.

Key-words: formal semantics, bare nouns, parameters. 


\section{REFERÊNCIAS}

BUNT, H. Mass Terms and Model-Theoretic Semantics. Cambridge Studies in Linguistics. Cambridge: University Press, 1985.

CARLSON, G. Reference to Kinds in English. New York, 1980. Dissertation (Ph.D) University of Massachusetts, Amherst.

CHIERCHIA, G. Reference to Kinds across Languages. Natural Language Semantics, $\mathrm{n}$. 6, p. 339-405, 1998.

CHUNG, S. On Reference to Kinds in Indonesian. Natural Language Semantics, v. 8, n. 2, p. 157-171, 2000.

DOWTY, D. R.; WALL, R. E.; PETERS, S. Introduction to Montague Semantics. Dordrecht, Holland: Reidel, 1981.

GOMES, A. P. Todo Nome versus Cada Nome. Trabalho apresentado no 8. SICUSP. 2000. Inédito.

MÜLLER, A. Genericity and the Denotation of Bare Nouns in Brazilian Portuguese. In: YOUNG, J.; VEERLE, A.(Ed.). UMass Occasional Papers. Issues in Semantics. No prelo.

NEGRÃO, E. V. Distributividade em PB e a Exigência de Quantificação sobre Eventos. In: Seminários em Teoria Gramatical, 5., 2001, São Paulo. Working Papers... São Paulo: Universidade de São Paulo.

PARTEE, B. H. Noun Phrase Interpretation and Type Shifting Principles. In: GROENENDIJK, J.; JONGH, D. de; STOKHOF, M. (Ed.). Studies in Discourse Representation Theory and the Theory of Generalized Quantifiers. Dordrecht: Foris, 1987. p.115-143.

PELLETIER, F. JNon-singular reference: some preliminaries. Philosophia, n. 5, 1975.

SCHMITT, C.; MUNN, A. Against the Nominal Mapping Parameter. Bare Nouns in Brazilian Portuguese. NELS, n. 29, 1999.

STOWELL, T. Subjects, specifiers, and X-bar theory. In: BALTIN, M. R.; KROCH, A. S. (Eds.). Alternative conceptions of Phrase. Chicago: University of Chicago Press, 1989. p. 232-262. 